RAD Conference Proceedings, vol. 4, pp. 113-117, 2020

ISSN 2466-4626 (online) | DOI: 10.21175/RadProc.2020.24

www.rad-proceedings.org

\title{
BIOMECHANICS OF VERTEBRAL COLUMN AFTER PERFORMING MODIFIED PARTIAL LATERAL CORPECTOMY ${ }^{*}$
}

\author{
N.A. Kozlov, A.A. Oleshkevich ${ }^{* *}$, B. Bhattarai, S.V. Pozyabin
}

Federal State Budgetary Educational Institution of Higher Education "Moscow State Academy of Veterinary Medicine and Biotechnology - MVA by K. I. Skryabin” (Moscow SAVMB), Moscow, Russia

\begin{abstract}
To compare the influence of classical and modified partial lateral corpectomy in vertebral instability biomechanical studies was performed. The study was carried out on fresh sectional material (9 specimens each with two spinal segments L2-L3) from dogs of non-chondrodystrophic breeds, weighing from 25 to $35 \mathrm{~kg}$, who died from causes that did not cause any pathological changes in the thoracolumbar spine. Fragments of the spinal column were isolated by anatomical preparation, after which the soft tissue structures were removed as much as possible. Computed tomography was performed to exclude any structural changes in the vertebral column. Biomechanical studies were carried out on laboratorial modified UTS 11OM-10O and KTS 403-10O universal testing machine. The areas of elastic and plastic deformation, maximum torque, resistance of samples in different parts of the graph, residual deformation were determined. When comparing the areas of elastic deformations in different groups, the following data were obtained. In all groups of samples, a directly proportional relationship between the load and resistance of the samples was obtained. Native vertebral specimens are the most resistant to stress, the next in strength are specimens with modified partial lateral corpectomy, the least durable ones with classical partial lateral corpectomy. The greatest resistance was exerted by native spinal specimens. The maximum torque values were $(44.5 \pm 1.5) \mathrm{N} \cdot \mathrm{m}$. To reduce stability, the groups were arranged in the following order: the group with a classical partial lateral corpectomy [maximum value $(44.5 \pm 1.5) \mathrm{N} \cdot \mathrm{m}$ ], with a modified partial lateral corpectomy [maximum value $(49.5 \pm 0.5) \mathrm{N} \cdot \mathrm{m}]$. The difference in indicators indicates the possibility of both changing the modulus of the radius vector and the angle between the vector indicated and the direction of the acting force. The values of rotation angles at which a transition from elastic to plastic deformation was observed were also different and amounted to $22.0^{\circ} \pm 1.0^{\circ}$ and $28.0^{\circ} \pm 1.0^{\circ}$ degrees. The native specimens of the spine proved to be the most resistant to force applied; specimens with modified partial lateral corpectomy were less resistant than native specimens but more resistant then specimens with partial lateral corpectomy. At the same time, the samples with modified partial lateral corpectomy differed little from the native samples.
\end{abstract}

Key words: Biomechanics, instability, partial lateral corpectomy, vertebral segment

\section{INTRODUCTION}

For the last 30 years in biomechanics, much attention has been paid to the problems of the practical use of the results of osteo-densitometry and modeling of the spinal cord.[2,3,4] In veterinary medicine, such direction of biomechanics as computer modeling of the specifics of work and functional features of different parts of the spine of domestic animals is just beginning to find its practical use.[5] In this article, we will focus only on the postoperative change of biodynamic in the moment of force of the thoracolumbar spine in dogs after the use of partial lateral corpectomy.

Degeneration of the intervertebral disc is a natural and inevitable part of aging and leads to a series of progressive disorders in the structure of the intervertebral disc in humans and animals [2,6,7]. However, this degenerative process is of minimal clinical significance if the extrusion / protrusion of the intervertebral disc does not lead to damage to the spinal cord or spinal nerves and the cause neurological problem $[2,5,8,9,10]$. Discopathy is one of the most common cause of paresis and paralysis in dogs $[2,7,11-$ 13]. Historically, there are two main types of degenerative disc diseases [6,7,9]. Hansen-I or extrusion of intervertebral discs occurs which is usually seen in chondrodystrophic dog breeds and involves the extrusion of the nucleus pulposus through all layers of the degenerated annulus fibrosus into the spinal canal $[6,9,14]$. Hansen-II type or protrusion of the intervertebral disc is mainly found in nonchondrodystrophic dogs of medium and large breed $[13,14,15]$. The weakened hypertrophied annulus is displaced dorsally into the spinal canal, resulting in chronic progressive spinal cord compression. There are the following data on localization of extruded disc materials contents within spinal canal in dogs: lateral localization $-64 \%$, ventral and simultaneous lateral

\footnotetext{
* The material that served as the basis for this article was presented at the $8^{\text {th }}$ RAD-International Conference [1].

** kompsotita@gmail.com
} 
N.A. Kozlov et al., Biomechanics of vertebral column..., RAD Conf. Proc., vol. 4, 2020, 113-117

location of herniated material-15.5\%, ventral localization $-18 \%$, dorsal localization $-1.5 \%$ [16].

With the development of modern technologies, such as computed tomography and magnetic resonance imaging, timely diagnosis and selection of the correct treatment for dogs with intervertebral disc disease has become much easier. But a uniform methodology for timely and correct diagnosis and treatment of dogs with chronic extrusion/ protrusion of the intervertebral disc has not yet been established.

Dorsal laminectomy, hemilaminectomy, minihemilaminectomy, and foraminotomy are the surgical options used in dogs with chronic extrusion/ protrusion of the intervertebral disc causing mild or severe neurologic deficits. But the above mentioned surgical procedures do not provide sufficient visualization of the extruded/protruded intervertebral disc, which causes compression of the spinal cord and is located ventrally, without manipulation of the spinal cord, and can cause iatrogenic injury, the complete removal of which is almost impossible. Partial lateral corpectomy, first described by P. Moissonnier et. al., 2004 [13], is one of the methods of surgical intervention in dogs with chronic extrusion/ protrusion. But, some studies showed that after surgical intervention mentioned above in some extent cause instability in vertebral column. So, aim of this study is to compare biomechanics of spinal segments after performing partial lateral corpectomy, modified partial lateral corpectomy and intact spine in cadaver materials.

\section{MATERIALS AND METHODS}

The study was carried out on fresh sectional material (9 specimens each with two spinal segment L2-L3) from dogs of non-chondrodystrophic breeds, weighing from 25 to $35 \mathrm{~kg}$, who died from causes that did not cause any pathological changes in the thoracolumbar spine. Fragments of the spinal column (L2-L3) were isolated by anatomical preparation, after which the soft tissue structures were removed as much as possible. Computed tomography was performed to exclude any structural changes in the vertebral column.

Using a Dremel 300 high-speed burr laminas of the adjacent vertebrae were removed, distal to the articular process. After approaching the dorsal longitudinal ligament in the spinal canal, it was removed for better visualization of the spinal cord. Then a needle was inserted into the intervertebral disc to determine its location and the angle of hole in the vertebral body. To assess the volume of cut, computed tomography was performed before and after milling.

Partial lateral corpectomy was performed as described by P. Moissonnier with colleagues [5,13]. Modified partial lateral corpectomy was performed on cranial part of caudal vertebrae.

Compared to classical partial lateral corpectomy (Fig. 1A.), during modified partial lateral corpectomy either caudal part of cranial vertebral body (Fig. 1B-a) or cranial part of caudal vertebral body (Fig. 1B-b) is rejected depending upon localization of extruded/protruded disc material. If disc material is located centrally, only cranial part of caudal vertebral body is rejected. This technique seems to be clinically more relevant because is less traumatic, reduces time of surgery and reduces instability in vertebral column. In this study classical and modified partial lateral corpectomy is compared with biomechanical point of view which was not performed before.
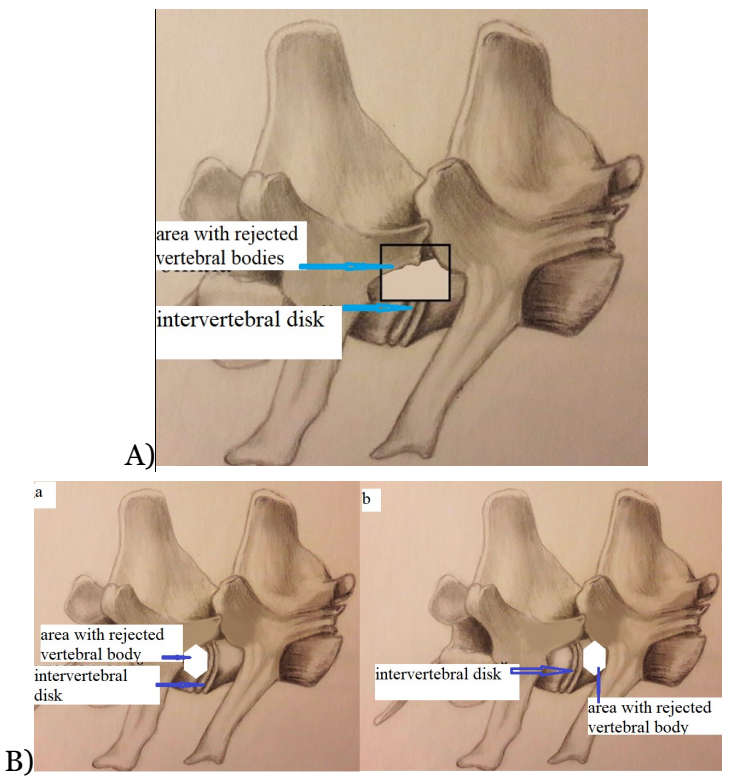

Figure 1. Schematic illustration of

classical A and modified partial lateral corpectomy B.

Biomechanical studies were carried out on a UTS 110M-100 and KTS 403-100 universal testing machine. The areas of elastic and plastic deformation, maximum torque, resistance of samples in different parts of the graph, residual deformation were determined. A total of 9 samples were examined. Three vertebral specimens in each group: partial lateral corpectomy, modified partial lateral corpectomy and control groups.
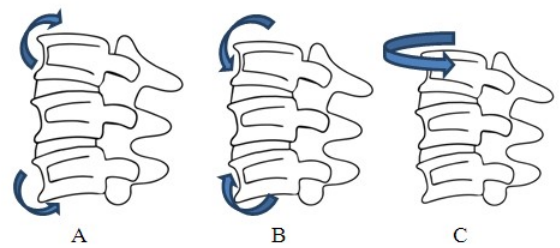

Figure 2. Schematic illustration of A-flexion, B-extension and C-rotation of spinal segments

As part of the study, the vertebral segments were tested for flexion, extension, and rotation. The test procedure is shown above schematically (Fig.2).

Flexion and extension tests were carried out on a laboratorial modification of the UTS $110 \mathrm{M}-100$ universal testing machine. During the test following force measurement range was applied: tension/ compression; range of measured loads, $\mathrm{kN}$ : 0.001-100; load measurement error: $\leq 1 \%(0.5 \%)$ of indication, up to $1 / 100$ of the permissible load. 
Twisting tests were performed on a KTS 403-100 device. The diameter of the samples clamped into the grippers was, mm: 0.2-8; adjustable distance between grippers, $\mathrm{mm}$ : 100-650; rotation frequency, $\mathrm{r} / \mathrm{m}$ : $0.05-50$; tension force setting range, $10-500 \mathrm{~N}$.

During the experimental test maximum applied rotational force, moment of force, angular and linear displacement, and time were measured. After testing, the mean displacements, standard deviation and stiffness were evaluated. For the stiffness of the sample, the linear regression coefficient in the displacement space was taken: the load, the characteristic form of the diagram, and linear regression (Fig.3).

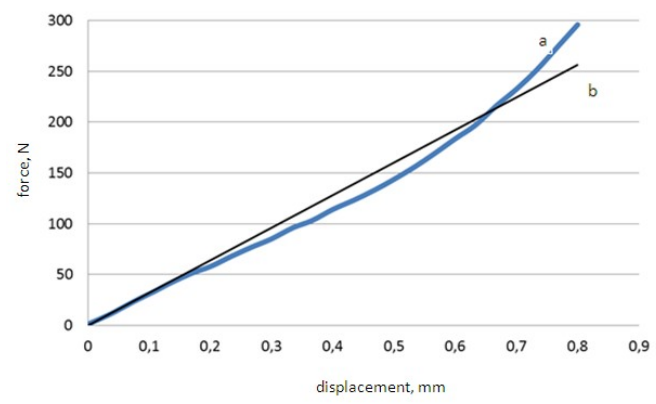

Figure 3. Linear representation of the stiffness of the sample; a (blue line) - characteristic diagram, b (black line) linear approximation)

\section{RESULTS}

Following results were obtained during biomechanical studies performed in our study.

In the flexion tests, loading was performed at the rate of $1 \mathrm{~mm} / \mathrm{min}$. up to $300 \mathrm{~N}$ (Fig.3), in the extension at the rate of $1 \mathrm{~mm} / \mathrm{min}$ up to $700 \mathrm{~N}$. The approximation line (Fig. 3b) should not be considered because the classical power-law of dependence $y=x^{2}$ was obtained, constructed based on experimental data.

In flexion tests in the control group $(\mathrm{p}<0.05)$, displacements were $0.72 \cdot 10^{-3} \mathrm{~m}(17 \%)$, in group $1-2.0410^{-3} \mathrm{~m}(7 \%)$, in group $2-1.79 \cdot 10^{-3} \mathrm{~m}(14 \%)$. In bending tests $(\mathrm{p}<0.05)$ in the control group, the rigidity was $441 \cdot 10^{3} \mathrm{~N} / \mathrm{m} \quad(14 \%)$, in group $1-264 \cdot 10^{3} \mathrm{~N} / \mathrm{m}(17 \%)$, in group $2-199 \cdot 10^{3} \mathrm{~N} / \mathrm{m}$ (28\%).

In the extension tests, in the control group, displacements were $(\mathrm{p}<0.05) \quad 0.85 \cdot 10^{-3} \mathrm{~m}$, in group $1-1.40 \cdot 10^{-3} \mathrm{~m}$, in group $2-2.01 \cdot 10^{-3} \mathrm{~m}$. In the extension tests, in the control group stiffness was $1,111 \cdot 10^{3} \mathrm{~N} / \mathrm{m}$, in the group $1-621 \cdot 10^{3} \mathrm{~N} / \mathrm{m}$, group $2-381 \cdot 10^{3} \mathrm{~N} / \mathrm{m}$.

To evaluate the symmetry of stiffness, the flexion stiffness ratio was taken as a percentage of extension stiffness. In the control group, this value was $40 \%$, in group $1-43 \%$, \& in group 2 the flexion stiffness ratio was $52 \%$. This indicator was at maximum force applied - $85 \%, 89 \%$ and $145 \%$, respectively (Figs. 4,5 ).

In the control group, the twisting angle was $24.5^{\circ} \pm$ $0.71^{\circ}(4 \%)$, in the group $1-28^{\circ} \pm 1.0^{\circ}(5 \%)$, in the group 2 the twisting angle was $22^{\circ} \pm 1.0^{\circ}(3 \%)$ (Fig. 6A). In the flexion tests in the control group the stiffness was $47 \pm 1.41 \mathrm{~N} \cdot \mathrm{m}$; group $1-49.5 \pm$ $0.5 \mathrm{~N} \cdot \mathrm{m}$, group $2-44.5 \pm 1.5 \mathrm{~N} \cdot \mathrm{m}$ (Fig.6B).

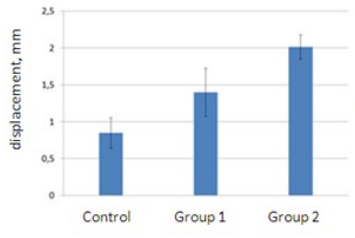

A

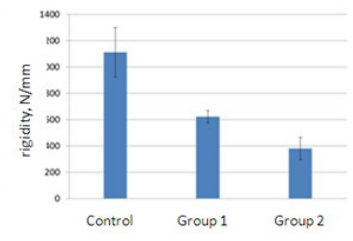

B
Figure 4. Results of biomechanical studies of specimens of the vertebral motor segment extension: A - displacement, B - rigidity

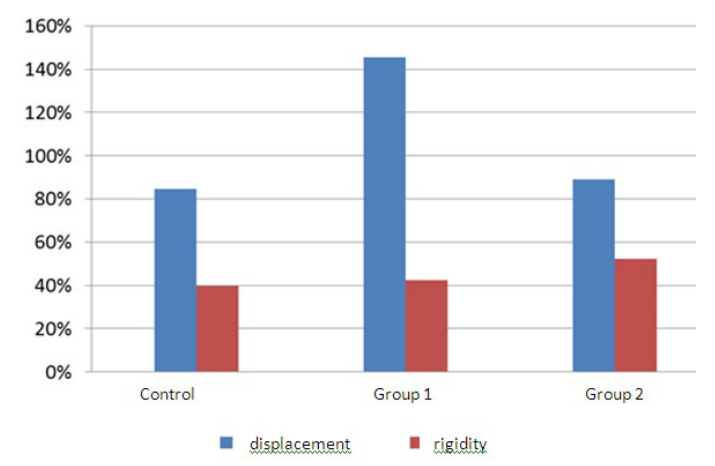

Figure 5. Results of biomechanical studies of spinal motor segment samples for extension in the study groups. In the torsion tests, loading was performed at a rate of $1 \mathrm{deg} / \mathrm{min}$. up to $20 \mathrm{~N} / \mathrm{m}$

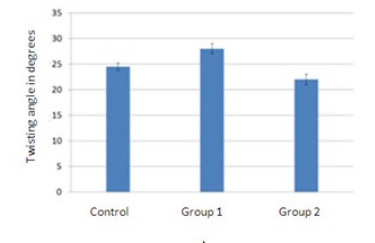

A

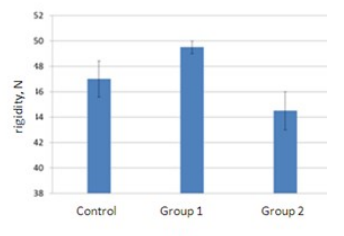

B
Figure 6. Results of biomechanical studies of samples of the vertebral segment twisting: A - twisting angle, B - rigidity

Thus, on the basis of these biomechanical studies, it can be concluded that a modified partial lateral corpectomy reduces the instability of the spinal column.

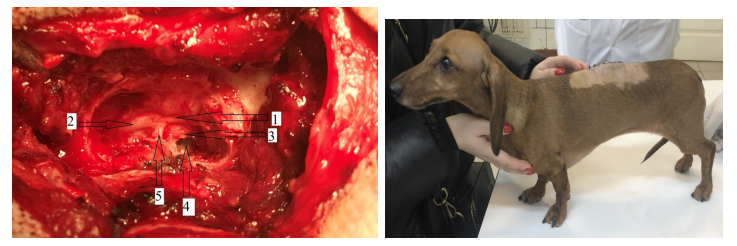

Figure 7. Partial lateral corpectomy performed at L1-L2 level in a 4-year-old female dachshund: A (left). 1 - region where spinal cord is compressed by protruded intervertebral disk, 2 - spinal cord, 3 - protruded intervertebral disk, 4 - area with partial lateral corpectomy, 5 - spinal nerve. B (right) Same dog 4 days after surgery undergoing rehabilitation. 
Intraoperative image (Fig. 7A, B) below illustrates one of partial lateral corpectomies successfully performed in the patient from our clinic.

During the year of 2019-2020 modified partial lateral corpectomy was successfully performed in 57 dogs of different breeds, ages and sizes. Among them 17 were chondrodystrophic and 40 nonchondrodystrophic breeds. Surgical time was reduced in average by 40 minutes and post rehabilitation time was reduced twice compared to study performed previously by Flegel et al. [8] using classical method which makes this method one of the most effective, practical and actual in modern veterinary vertebrology.

\section{DISCUSSION}

Biomechanical study of samples of the vertebral segments, we obtained data reflecting the degree of destruction of its various structures. Thus, in the zone of elastic deformations, a direct proportional relationship was observed between the angle of rotation and the resistance of the sample.

A comparative analysis of the areas of elastic deformations in all groups showed a direct proportional relationship between the force and resistance of the samples. The greatest resistance to angle of rotation was shown by native samples of the spine. The maximum values of the torsional stiffness were $47 \pm 1.41 \mathrm{~N} \cdot \mathrm{m}$. According to the decrease in resistance to stress, the groups were distributed in the following order: (partial lateral corpectomy) group-2 (with maximum value of $44.5 \pm 1.5 \mathrm{~N} \cdot \mathrm{m}$ ), (modified partial lateral corpectomy) group-1 - (maximum value $49.5 \pm 0.5 \mathrm{~N} \cdot \mathrm{m}$ ). The values of the angles of rotation at which the transition from the elastic region to the plastic deformation region was noted were practically equivalent: $22^{\circ} \pm 1.0^{\circ}-28^{\circ} \pm 1.0^{\circ}$ degrees.

The native specimens of the spine proved to be the most resistant to force applied; specimens with modified partial lateral corpectomy were less resistant than native specimens but more resistant then specimens with partial lateral corpectomy. At the same time, the samples with modified partial lateral corpectomy differed little from the native samples.

The greatest resistance to flexion was provided by native samples of the spine. The maximum value of flexion stiffness was $441 \pm 6.1 \mathrm{~N}$. According to the decrease in resistance to load, the groups were arranged in the following order: the group with modified partial lateral corpectomy (maximum value $264 \pm 7.4 \mathrm{~N}$ ), with classical partial lateral corpectomy (maximum value $-199 \pm 3.3 \mathrm{~N}$ ).

The most resistant to stress were native samples of the spine, followed by samples with modified partial lateral corpectomy, the least durable - with classical partial lateral corpectomy.

The greatest resistance to extension was experienced by native samples of the spine. In this case, the maximum values of the extension stiffness were $1111 \pm 1.88 \mathrm{~N}$. According to the parameters of reducing resistance to this type of loading, the groups were arranged in the following order: the group with modified partial lateral corpectomy (maximum value
$621 \pm 4.5 \mathrm{~N}$ ), with classical partial lateral corpectomy (maximum value $381 \pm 8.3 \mathrm{~N}$ ).

Comparative biomechanical study in cadaver specimens performed previously by Reves et al. [16] showed that partial lateral corpectomy leads to vertebral column instability and if combined with hemilaminectomy it enhances instability. In this study, comparative study between biomechanics after hemilaminectomy and partial lateral corpectomy was not performed, but instead biomechanics after performing partial lateral corpectomy and modified partial lateral corpectomy were compared (Fig. 1 A,B \& Fig. 7). Articular process plays significant in stability of vertebral column [16] and is usually removed during hemilaminectomy which is supposed to be one the cause of vertebral instability, which is not always removed during partial lateral corpectomy, so combined surgical procedure should obviously increase vertebral instability. In this study, both classical and modified partial lateral corpectomy were performed without removing articular processes for more accurate biomechanical comparison.

\section{CONCLUSION}

The most resistant to stress were native specimens of the spine, followed by specimens with modified partial lateral corpectomy in strength, and specimens with classical partial lateral corpectomy were the least durable.

Surgical manipulations, such as dorsal laminectomy, hemilaminectomy, partial lateral corpectomy during decompression of the spinal cord on the spinal column, create a certain degree of instability; hemilaminectomy increases the instability of the spine if combined with partial lateral corpectomy. The results of our study showed that during the classical partial lateral corpectomy, instability of the spinal column is present, but when the modified partial lateral corpectomy is performed, it is reduced by 2 times.

Any surgical interventions in the area of the spinal column can provoke its instability. The technique of performing lateral partial corpectomy is designed in such a way as to minimize the amount of intervention in the vertebral column, which, in turn, reduces its instability.

\section{REFERENCES}

1. N. A. Kozlov, A. A. Oleshkevich, B. Bhattarai, "Biomechanical study of vertebral column after performing modified partial lateral corpectomy in dogs," in Book of Abstr. 8th Int. Conf. Radiation and Applications in Various Fields of Research (RAD 2O2O), Budva, Montenegro, p. 7, 2020.

Retrieved from:

https://www.rad-conference.org/Book of AbstractsRAD 2020.pdf

Retrieved on: Sept. 23, 2020

2. Y. Zheng, W.W. Lu, Q. Zhu L. Qin, S. Zhong, J. C. Leong, "Variation in bone mineral density of the sacrum in young adults and its significance for sacral fixation," Spine, vol. 25, no. 3, pp. 353-357, 2000. https://doi.org/10.1097/00007632-200002010-00016 
N.A. Kozlov et al., Biomechanics of vertebral column..., RAD Conf. Proc., vol. 4, 2020, 113-117

PMID: 10703109

3. В. В. Рерих, М. У. Байдарбеков, М. А. Садовой, Н. Д. Батпенов, И. А. Кирилова, "Хирургическое лечение переломов грудных и поясничных позвонков с использованием транспедикулярной пластики и фиксации," Хирургия позвоночника, т. 14, № 3, c. 54-61, 2017 (V. V. Rerikh, M. U. Baiderbekov, M.A. Sadovoy, N. D. Barpenov, L.A. Kirilova, "Surgical tratment of thoracic and lumbar spine fractures using transpedicular vertebroplasty and fixation," Spine Surgery, vol. 14, no. 4, pp. 54-61, 2017.)

Retrieved from:

https://cyberleninka.ru/article/n/hirurgicheskoe-

lechenie-perelomov-grudnyh-i-poyasnichnyhpozvonkov-s-ispolzovaniem-transpedikulyarnoyplastiki-i-fiksatsii

Retrieved on: Jul. 17, 2020

4. M. Hofstetter, P. Gédet, M. Doherr, J. Ferguson, F. Forterre, "Biomechanical Analysis of the ThreeDimensional Motion Pattern of the Canine Cervical Spine Segment $\mathrm{C}_{4}-\mathrm{C}_{5}$," Veterinary Surgery, vol. 38, pp. 49-58, 2009. https://doi.org/10.1111/j.1532-950X.2008.00465.x

5. F. De Vicente, F. Bernard, D. Fitzpatrick, P. Moissonnier, "In vitro radiographic characteristics and biomechanical properties of the canine lumbar vertebral motion unit after lateral corpectomy, minihemilaminectomy and hemilaminectomy", Vet. Comp. Orthop. Traumatol., vol. 26, pp. 19-26, 2013. https://doi.org/10.3415/VCOT-12-02-0016

6. C. J. Downes, T. J. Gemmill, S. E. Gibbons, "Hemilaminectomy and vertebral stabilisation for the treatment of thoracolumbar disc protrusion in 28 dogs,” J. Small Anim. Pract., vol. 50, pp. 525-535, 2009. https://doi.org/10.1111/j.1748-5827.2009.00808.x

7. A. Filleur, "Benefit of thoracolumbar lateral corpectomy for chronic intervertebral disc disease in dogs: results of a 14 year retrospective study of 107 dogs in two veterinary teaching hospitals", Proceedings of the $21^{\text {st }}$ Annual Scientific Meeting European College of Veterinary Surgeons, Barcelona, Spain, p. 76, 2012. Retrieved from:

https://www.ivis.org/library/ecvs/ecvs-annualcientific-meeting-spain-2012/benefits-ofthoracolumbar-lateral-corpectomy Retrieved on: May 25, 2020.

8. T. Flegel et.al. "Partial lateral corpectomy of the thoracolumbar spine in 51 dogs: assessment of slot morphometry and spinal cord decompression", Vet Surg., vol. 40, pp. 14-21, 2011. https://doi.org/10.1111/i.1532-950X.2010.00747.x

9. N. D. Jeffery, J. M. Levine N. J. Olby, V. M. Stein "Intervertebral Disk Degeneration in Dogs: Consequences, Diagnosis, Treatment, and Future Directions", Journal of Veterinary Internal Medicine, vol. 27, no. 6, pp. 1318-1333, 2013. https://doi.org/10.1111/jvim.12183

10. L. A. Smolders et al., "Biomechanical assessment of the effects of decompressive surgery in nonchondrodystrophic and chondrodystrophic canine multisegmented lumbar spines", Eur. Spine J., vol. 21, pp. 1692-1699, 2012. https://doi.org/10.1007/s00586-012-2285-0

11. H. J. Hansen, "A pathologic-anatomical study on disc degeneration in dog, with special reference to the socalled enchondrosis intervertebralis", Acta Orthop. Scand. Suppl., vol. 11, pp. 1-117, 1952.

Retrieved from: https://pubmed.ncbi.nlm.nih.gov/14923291/ Retrieved on: June 3, 2020

12. A. Fujiwara et al., "The relationship between disc degeneration, facet joint osteoarthritis and stability of the degenerative lumbar spine", J. Spinal Disord, vol. 13, pp. 444-450, 2000. https://doi.org/10.1097/00002517-200010000-00013

13. P. Moissonnier, P. Meheust, C. Carozzo, "Thoracolumbar lateral corpectomy for treatment of chronic disk herniation: technique description and use in 15 dogs", Vet. Surg., vol. 33, pp. 620-628, 2004. https://doi.org/10.1111/j.1532-950X.2004.04085.x

14. A. Z. Akhtar, J. J. Pippin, C. B. Sandusky, "Animal studies in spinal cord injury: a systematic review of methylprednisolone", Altern. Lab. Anim., vol. 37, no. 1, pp. 43-62, 2009. https://doi.org/10.1177/026119290903700108

15. O. Besalti et.al., "The role of extruded disk material in thoracolumbar intervertebral disk disease: a retrospective study in 40 dogs", Can. Vet. J., vol. 46, pp. 814-820, 2005 .

Retrieved from:

https://www.ncbi.nlm.nih.gov/pmc/articles/PMC11877 91/ Retrieved on: June 15, 2020

16. V.N. Revés et.al., "Influence of partial lateral corpectomy with and without hemilaminectomy on canine thoracolumbar stability: a biomechanical study", Vet. Surg., vol. 41, no. 2, pp. 228-234, 2012. https://doi.org/10.1111/i.1532-950X.2011.00912.x 